\title{
ENTERRAMIENTOS PREHISTÓRICOS EN FOSA EN EL ENTORNO MEGALÍTICO DE Los Molares (MARgen iZquierda de la CUENCA DEl Bajo GuAdAlQuivir)
}

Prehistoric burials inside pits in the megalithic area of Los Molares (Eastern side of Lower Guadalquivir Basin)

DANIEL GARCÍA RIVERO, MARÍA BARRERA CRUZ, CRISTINA MARÍA LÓPEZ ORTÍN, EZEQUIEL GÓMEZ MURGA

Dpto. Prehistoria y Arqueología, Universidad de Sevilla. garciarivero@us.es (https://orcid.org/0000-0002-6112-3181), mariabarreracruz93@gmail.com (https://orcid.org/0000-0003-4928-5070),criloport@hotmail.com, egomezmurga@yahoo.es (https://orcid.org/0000-0002-9191-5413)

RESUMEN:

El artículo presenta nuevos datos procedentes de excavaciones recientes en Los Molares (provincia de Sevilla), en el entorno próximo de los dólmenes de El Palomar y Cañada Real. Los datos fueron obtenidos durante los trabajos arqueológicos previos a la urbanización de la finca de El Palomar, localizándose varias fosas rellenas con materiales prehistóricos, tres de ellas con restos humanos. Se presentan sus contextos arqueológicos y restos recuperados, así como los resultados de los análisis radiocarbónicos efectuados. Se realiza una discusión sobre las implicaciones de estos nuevos hallazgos en relación con el entorno megalítico conocido y con el registro funerario del IV milenio cal BC en

la margen izquierda de la cuenca del Bajo Guadalquivir.

Palabras clave: enterramientos, Neolítico, Calcolítico, megalitos, Guadalquivir.

Abstract:

The article provides new data from the recent archaeological excavations in the megalithic area of Los Molares (province of Seville). The archaeological interventions were carried out before the urbanization of the El Palomar area, near to the dolmens of El Palomar and Cañada Real, and they documented several prehistoric burials in three different pits. The archaeological contexts, the bioarchaeological information, the pottery and lithic sets, as well as the results of the radiocarbonic analyses are presented.A discussion is made on the historical implications of these new findings in relation to the previously known megalithic site and on the funerary archaeological record of the 4th millennium cal $B C$ on the Eastern of the Lower Guadalquivir basin.

Key words: burials, Neolithic, Copper Age, megaliths, Guadalquivir. 
El hallazgo arqueológico que se da a conocer en este artículo procede del casco urbano actual de la localidad de Los Molares, ubicada en el S de la provincia de Sevi1la. Se emplaza en la actual campiña sevillana, a medio camino entre el río Guadalquivir y las estribaciones occidentales de la Sierra Subbética, justo en el límite de la parte llana de la campiña y las suavemente onduladas estribaciones septentrionales de dicho sistema orográfico. Geológicamente, la parte al N del emplazamiento está caracterizada por calcarenitas, margas, yesos y calizas del Mioceno Superior-Plioceno, mientras que en la parte hacia el S predominan margas, areniscas y silexitas del Mioceno Inferior-Medio. En la época correspondiente al hallazgo que aquí nos ocupa, de finales del periodo Neolítico, el sitio se encontraba relativamente cerca, a menos de $20 \mathrm{~km}$, de la margen izquierda del paleoestuario del Guadalquivir, cuya orilla más próxima al sitio que ahora se presenta ha sido detectada en el entorno de la actual localidad de Los Palacios y Villafranca (Arteaga et al. 1995; Borja et al. 2018) (fig. 1).

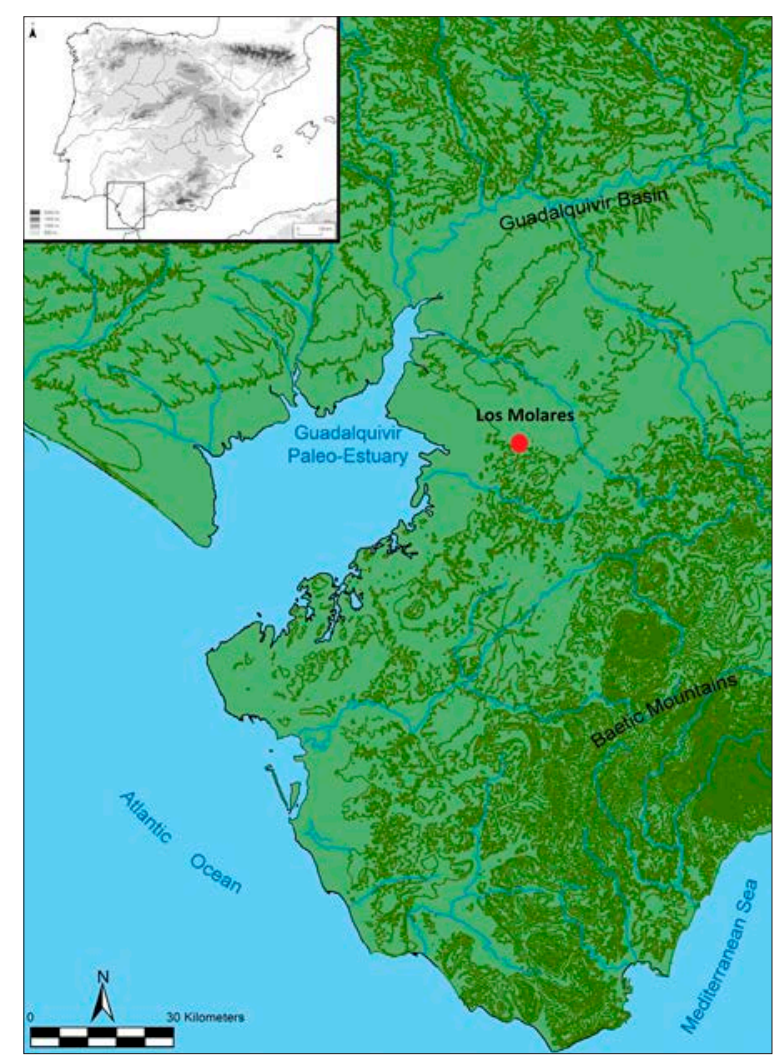

Fig. 1: Ubicación de Los Molares respecto al paleoestudario del Guadalquivir.
La historiografía arqueológica de Los Molares se remonta al menos a 1967, cuando se produjo, como consecuencia de la construcción de viviendas en el área septentrional del caso urbano, el hallazgo del Dolmen de Cañada Real I, el cual motivó las excavaciones arqueológicas dirigidas por Juan de Mata Carriazo, entonces Delegado de Zona del Servicio Nacional de Excavaciones y posteriormente Catedrático de la Universidad de Sevilla (Carriazo 1974). Labores agrícolas a escasa distancia de Cañada Real I hacia el O, concretamente en la finca de El Palomar, pusieron de manifiesto la existencia de otro monumento megalítico. Esto motivó las excavaciones arqueológicas de los años 1980 y 1981 por parte de Fernando Fernández Gómez, entonces Director del Museo Arqueológico de Sevilla, y de Diego Oliva y Manuel $\mathrm{M}^{\mathrm{a}}$ Ruiz, respectivamente, en el Dolmen de El Palomar (VVAA 1982: 122).

Además de las excavaciones mencionadas, durante la misma década de 1980 se produjeron otras investigaciones arqueológicas en la zona. Entre ellas hay que destacar las exploraciones de Rosario Cabrero García, entonces profesora del Departamento de Prehistoria y Arqueología de la Universidad de Sevilla. Con motivo de su tesis doctoral visitó y estudió parte de los ajuares (Cabrero 1988). Posteriormente, ella y sus colaboradores analizaron y publicaron buena parte de los materiales previamente rescatados (Cabrero et al. 1995; 1996; 2003a; 2005), y además excavaron el cercano asentamiento calcolítico del Amarguillo II (Cabrero 1990; Cabrero et al. 1997; 2003b). También hay que mencionar las investigaciones arqueológicas de Manuel $\mathrm{M}^{\mathrm{a}}$ Ruiz Delgado, que prospectó gran parte del entorno, específicamente los términos municipales de Los Molares y El Coronil (Ruiz Delgado 1985).

Los datos inéditos que ahora se presentan proceden de una intervención arqueológica preventiva efectuada en los años 2005 y 2006. Durante 2005 se produjeron hallazgos fortuitos durante unas obras de urbanización. Acto seguido se presentó un proyecto que posibilitó la intervención arqueológica en el área. Estas labores arqueológicas fueron dirigidas por Ezequiel Gómez Murga y por Gilberto Rodríguez González, en el marco de la empresa arqueológica GEAS.

Los objetivos del presente trabajo son dar a conocer los enterramientos en fosa prehistóricos documentados en dicha intervención arqueológica, los cuales se sitúan en un rango cronológico correspondiente a los tradicionales periodos de Neolítico final y Calcolítico. Se presentan 
los enterramientos y sus estructuras arqueológicas, así como los análisis antropológicos, ceramológicos, líticos y radiocarbónicos. Finalmente se realiza una discusión que contextualiza espacial y cronológicamente este hallazgo no sólo en su entorno inmediato, sino también en el marco regional de la cuenca baja del Guadalquivir y piedemonte occidental subbético.

\section{TÉCNICAS Y MÉTODOS}

Al comienzo de la intervención arqueológica se encontraron algunas estructuras seccionadas por parte de los trabajos previos de urbanización de la finca. Una vez autorizada, la intervención arqueológica contó inicialmente con una prospección intensiva de la zona y una limpieza superficial de la capa removida de labor hasta la cota superior de las estructuras negativas. La excavación arqueológica alcanzó un área total de $300 \mathrm{~m}^{2}$ aproximadamente, y también se realizó un control de movimientos de tierra en las áreas periféricas de menor grado de afección arqueológica (Gómez et al. 2005). La excavación de las estructuras negativas se produjo atendiendo a la definición de las interfaces de las unidades estratigráficas (Harris 1991), de forma que todo el material y muestras arqueológicas quedaron debidamente registrados en sus correspondientes estratos. Cada una de las estructuras identificadas recibió un número de unidad estratigráfica específico, así como cada uno de sus correspondientes estratos de depósito.

La identificación y clasificación de los restos humanos y el análisis paleopatológico han seguido parámetros habituales de diversos trabajos especializados (Brothwell 1993; Burns 2008; Cabrero et al. 1995; Campillo 1993; Campillo y Subirá 2004; Chimenos et al. 1999; Egocheaga y Trabazo 2000; Isidro y Malgosa 2003; López Lázaro et al. 2013). El análisis se ha efectuado tras una selección sistemática de los restos, principalmente los cráneos y las piezas dentales. La mayor parte de los huesos postcraneales presenta un estado de conservación muy pobre, pero ha sido considerada para explorar y corroborar inferencias obtenidas a partir de aquellas piezas principales.

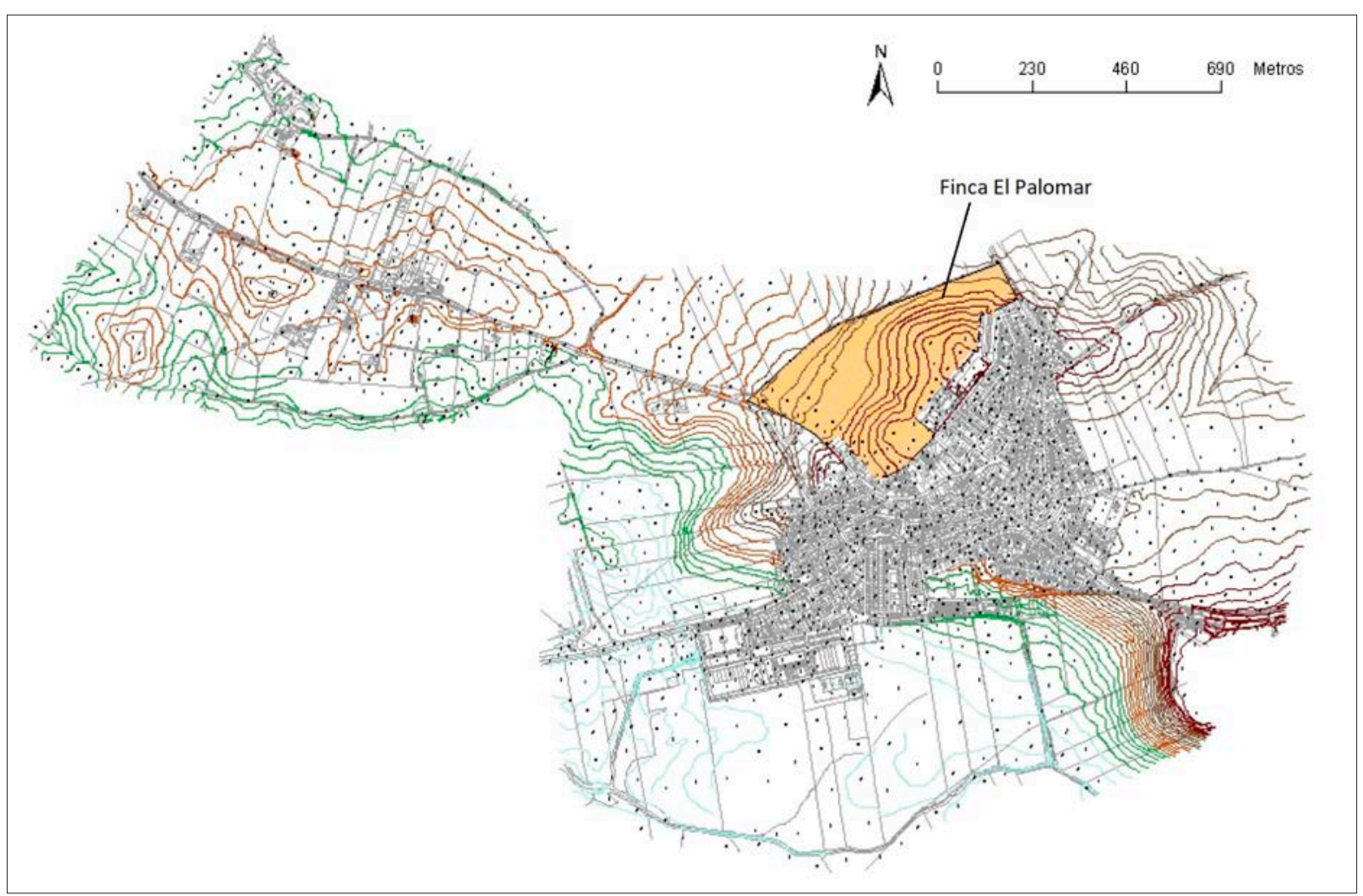

Fig. 2: Localización de la finca en el plano topográfico de Los Molares (a partir de Gómez et al. 2005: 58). 


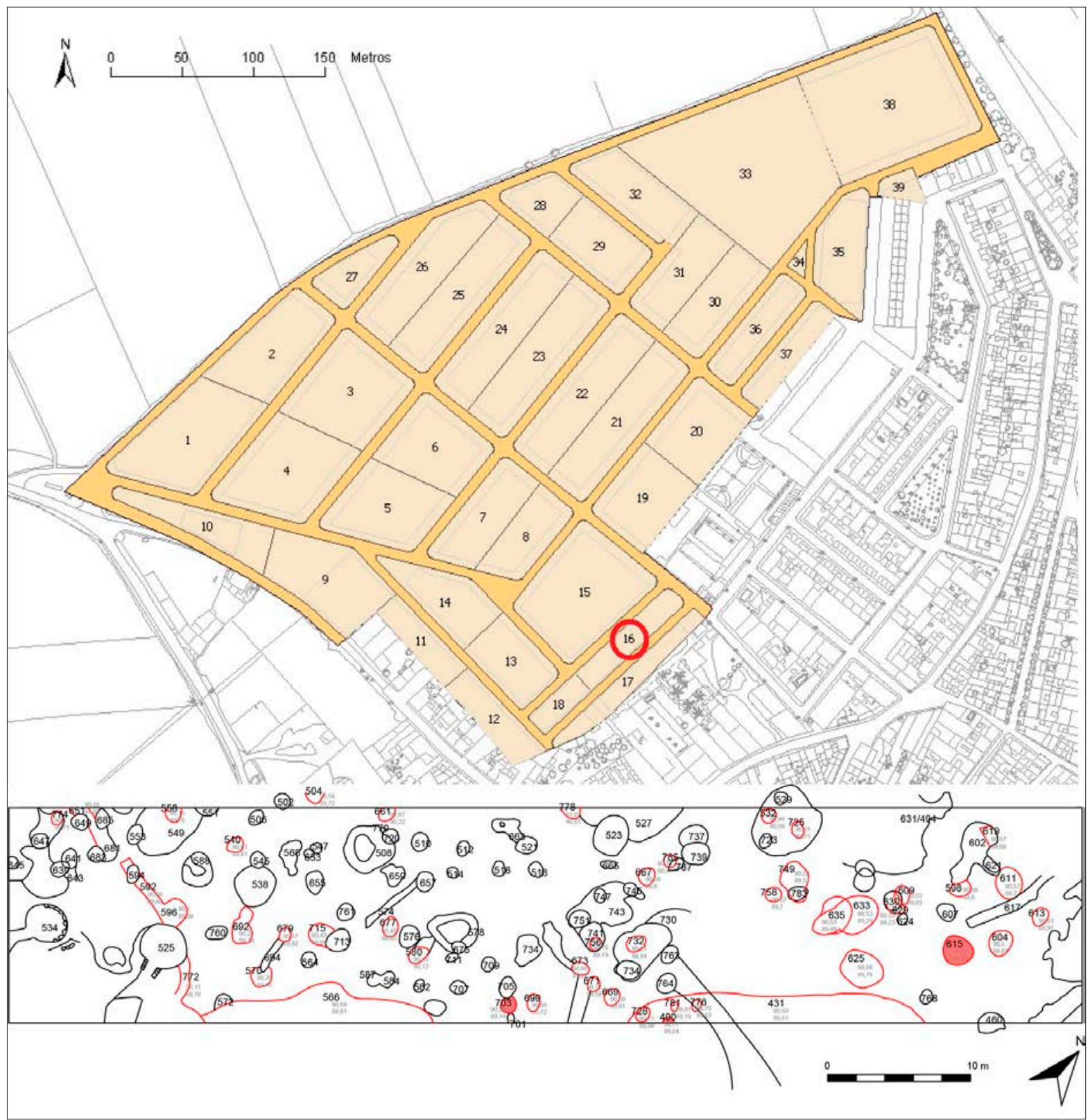

Fig. 3: Arriba: Ubicación de la Manzana 16 en la finca, a partir de Gómez et al. (2005: 55). Bajo: Planimetría arqueológica de la Manzana 16 (en líneas rojas, las estructuras con materiales prehistóricos; coloreado interno en las tres estructuras con restos óseos).

El material cerámico se ha pesado y contabilizado según los distintos estratos de cada estructura. Las cuantificaciones absolutas que se presentan hacen referencia al número de fragmentos, y no a una estimación del número de recipientes, aunque sí se han tratado unitariamente los fragmentos que conectan físicamente entre sí. Los dibujos presentados suponen una selección representativa, en términos morfométricos, de la diversidad del conjunto de cada estrato.

La industria lítica se ha clasificado en dos grandes apartados: lítica tallada y piedra pulimentada. El estudio de las técnicas de talla se ha basado en la tipología analítica de Laplace (1966) en cuanto al retoque y a las técnicas de extracción, y se ha completado con la definición 
de determinados atributos técnicos mediante la metodología de Bernaldo-Quirós et al. (1981). La tipometría del material ha sido establecida siguiendo la propuesta de Bagolini (1968). Con carácter general, la industria lítica se ha clasificado en Material Retocado o Material Sin Retocar. El primer apartado comprende los útiles u hojas $\mathrm{y}$ lascas retocadas, mientras el segundo se compone de hojas y lascas sin retocar, núcleos, esquirlas o restos de talla informes y productos de acondicionamiento, así como de chunks. La definición de ciertos aspectos morfológicos, tales como el tipo de retoque, se ha realizado mediante observación con lupa binocular. El análisis tecnotipológico se ha completado metodológicamente considerando las principales síntesis y propuestas de léxico elaboradas para las zonas occidental (Carvalho 1998; Carvalho y Gibaja 2005) meridional (Martínez y Afonso 2008) y oriental (Juan-Cabanilles 2008) de la península Ibérica.

Se han llevado a cabo dataciones radiocarbónicas sobre dos muestras óseas humanas procedentes de dos estratos diferentes de una misma estructura negativa (400). Las muestras se han analizado en el Centro Nacional de Aceleradores de Sevilla. Las fechas se refieren a la edad de muerte de los individuos analizados, y se asumen como indicadores cronológicos de los estratos que los contienen.

\section{RESULTADOS}

\section{LAS ESTRUCTURAS Y CONTEXTOS ARQUEOLÓ- GICOS}

La intervención arqueológica se llevó a cabo previamente a la urbanización de la franja septentrional del actual casco urbano de la localidad de Los Molares, en la conocida como finca El Palomar (fig. 2). Dado que ésta se ha dedicado tradicionalmente a olivar $u$ otros cultivos de secano, se encontraba en toda su superficie una capa arada de unos $30 \mathrm{~cm}$ de profundidad que alcanzaba la capa geológica de margas o cualquier estructura antrópica conservada. Las estructuras antrópicas por tanto se encontraban siempre afectadas en sus cotas superiores, de forma que no se conservaron sus correspondientes niveles de suelo. Apenas se pueden establecer relaciones estratigráficas entre ellas, al margen de algunas superposiciones casuales.

En la parte más meridional de la finca, concretamente en la Manzana 16, correspondiéndose con las cotas superiores de la mesa que supone la suave elevación natural

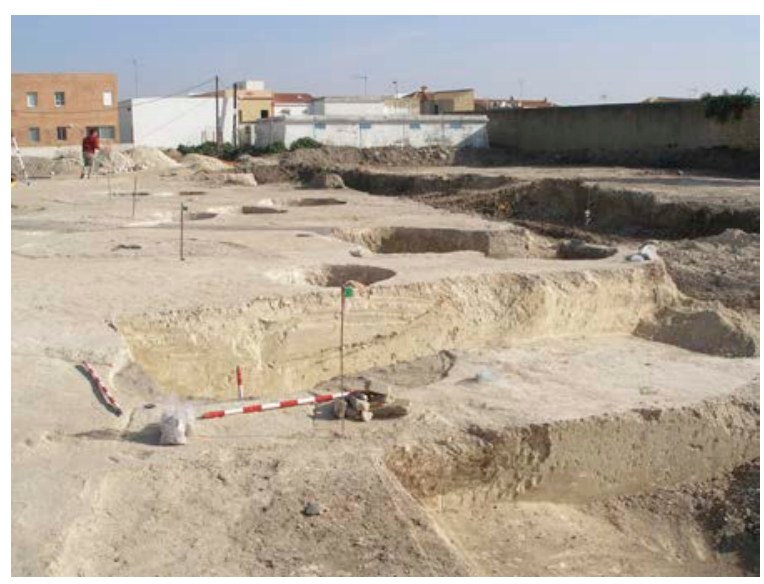

Fig. 4: Vista parcial desde el centro hacia la mitad E de la Manzana 16 con estructuras negativas excavadas.

sobre la que se asienta la localidad actual, se documentaron numerosas estructuras negativas con gran variabilidad de formas y tamaños. A tenor de los materiales arqueológicos de sus respectivos depósitos, algunas son prehistóricas, si bien la mayoría datan de épocas protohistórica, romana e históricas (figs. 3 y 4). Los depósitos de relleno de las estructuras prehistóricas suelen ser de tonalidades más claras y rojizas que los de las posteriores, tal vez debido a una menor cantidad de materia orgánica.

Destacan tres estructuras prehistóricas con restos humanos, que suponen el objeto de estudio del presente trabajo. Las ubicadas más al $\mathrm{S}$ se denominan estructuras 703 y 400, y apenas distan 10 m entre sí. Aproximadamente a $20 \mathrm{~m}$ al $\mathrm{N}$ de la última se localiza la estructura 615. Se trata de estructuras excavadas en la marga natural, cuyos rellenos suelen presentar distintas unidades deposicionales, usualmente de sedimentos con tonalidades marrones y texturas arcillosas. El material arqueológico está muy fragmentado y rodado. Además de las cerámicas y líticos, que se presentan pormenorizadamente más adelante, se encuentra una cantidad relativamente baja de restos faunísticos, usualmente fragmentados en forma de esquirlas, sin que puedan derivarse deposiciones intencionadas asociadas a los enterramientos.

La estructura 400 se encontraba parcialmente seccionada. En planta presenta morfología circular y en sección una forma acampanada ligeramente cilíndrica en su tercio superior y una base plana (fig. 5, a). Sus dimensiones máximas son 1,20 m de diámetro y 1,70 m de altura (conservada). El relleno estaba conformado por seis estratos deposicionales, denominados 401 a 406 desde arriba 

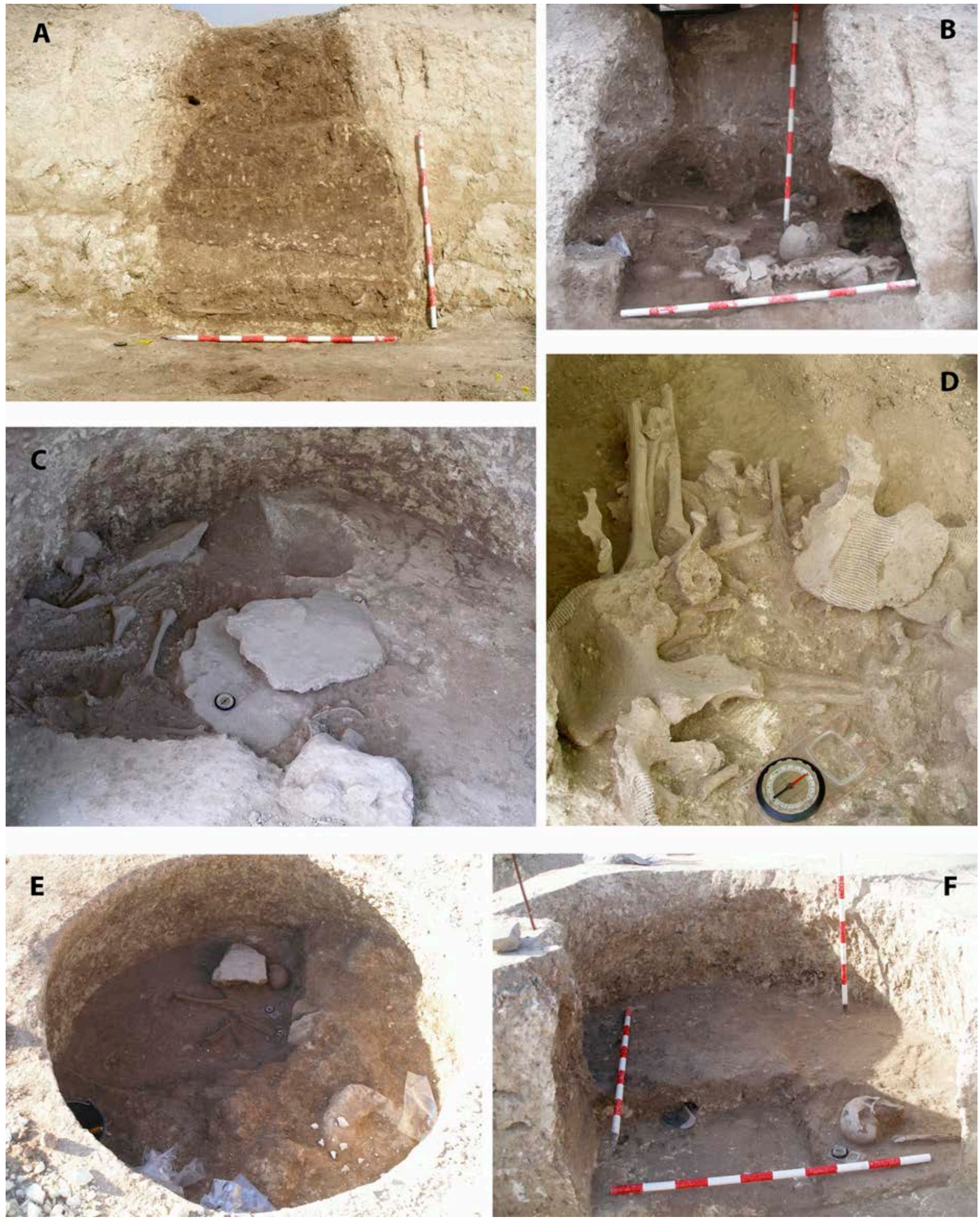

Fig. 5: Fotografías de las fosas y depósitos funerarios: (a) Sección de la estructura 400; (b) Depósito UE 403; (c) Interfaz superior del depósito UE 406; (d) Detalle del depósito UE 406; (e) Inhumación en UE 638; y (f) Restos en UE 704. 
hacia abajo. De ellos, el estrato basal (406) y uno intermedio (403) contaban con enterramientos humanos. El primero (fig. 5, d) es de color marrón pardo y textura arcillosa, y contiene algunos nódulos de marga. Este nivel de enterramientos está sellado por un estrato (405) de margas relativamente compacto sobre el que se encuentran diversos bloques calcáreos envueltos en un sedimento arcilloso de color marrón más claro, y tiene mayor cantidad de fragmentos de fauna (fig. 5, c). El segundo nivel de enterramientos (403) tiene un sedimento ligeramente más oscuro, de textura igualmente arcillosa y, entre las inhumaciones, piedras de mediano tamaño y nódulos de marga (fig. 5, b).

La estructura 615 es de forma circular en planta y acampanada en sección. Sus dimensiones conservadas son 2,20 m de diámetro y 1,13 m de altura. Su relleno estaba conformado por tres estratos deposicionales, desde arriba hacia abajo: 616, 637 y 638. Los tres niveles presentan una textura arcillosa, cuyos colores marrones rojizos tienden a tonalidades más o menos oscuras en función de la cantidad relativa de nódulos margosos que contienen. El nivel basal (638) contenía una inhumación (fig. 5, e), y está sellado por un potente estrato (637) con gran cantidad de marga, algunos fragmentos de adobe endurecido y numerosos bloques calcáreos, entre los que destaca uno con una cazoleta labrada en su cara más plana. Otro de esos bloques está justamente sobre la inhumación, cubriendo particularmente algunas vértebras cervicales y algunos huesos largos. La unidad superior (616) contiene mayor cantidad de material arqueológico, y algunas piedras termoalteradas.

La estructura 703 es muy similar a la anterior. También es de forma circular y sección acampanada, aunque la altura conservada es inferior. Concretamente, sus dimensiones son 1,90 de diámetro máximo y 0,70 de altura. La afección de esta estructura es notable. En el depósito que la colmata sólo se documenta un único estrato (704), de textura arcillosa y con leves diferencias espaciales arbitrarias dada la cantidad relativa y concentraciones de nódulos margosos. En él se han hallado un cráneo y un hueso largo humanos aislados (fig. 5, f).

Algunas de las inhumaciones estaban parcialmente desarticuladas, apareciendo mezclados los restos de distintos individuos, pero se ha podido determinar el mínimo número de individuos de cada unidad, así como su diagnóstico de edad y sexo. Algunos de los enterramientos se corresponden sin duda con inhumaciones primarias. En cualquier caso, los cuerpos no parecen haber sido colocados con cuidado, sino que tal vez fueron arrojados dadas sus posturas casuales. Normalmente, los estratos de carácter funerario contienen materiales cerámicos y líticos, así como restos de animales (bóvidos, caprinos, suidos, aves y pequeños mamíferos), aunque su alta fragmentación, baja integridad y arbitraria ubicación espacial limitan su interpretación como ofrendas funerarias.

\section{BIOARQUEOLOGÍA DE LOS RESTOS HUMANOS}

La estructura 400 tiene dos estratos con enterramientos múltiples, mientras que las otras dos estructuras (615 y 703) contienen sendos enterramientos, el primero una posible inhumación primaria y el segundo sólo un cráneo y un húmero.

La primera, la estructura 400 , contiene un estrato basal (unidad 406) donde se determinan cuatro individuos ( $n^{\circ} 4,5,6$ y 7), sin conexión anatómica, lo que denota sus correspondientes deposiciones accidentales (fig. 6). Es probable que uno de ellos (individuo 5), tras la desaparición de los tejidos blandos, fuera desplazado y arrinconado cuando se depositan los otros tres cuerpos. Éstos se corresponden con dos hombres (individuos 6 y 7) de 2030 y 25-30 años, respectivamente, y una mujer (individuo 4) de 20-22 años, mientras que aquél (individuo 5), de unos 17 años aproximadamente, no se ha determinado sexualmente. Encima de este estrato hay otros dos (UE 405 y 404) sin restos humanos ni huesos de animales. Sobre éstos se encuentra el otro estrato con carácter funerario (UE 403), tratándose de un enterramiento múltiple compuesto por los restos en conexión anatómica de tres hombres (individuos 1,2 y 3 ) de entre 20 y 25 años (fig. 6). Sobre él se documentan dos capas más de sedimentos (UE 402 y 401) en las que se han encontrado fragmentos de huesos de animales y de cerámicas en pequeñas cantidades.

En la estructura 615 sólo fue enterrada una persona (individuo 8), de sexo indeterminado y de 20-25 años, con relativa conexión anatómica, en su estrato basal (638) (fig. 6). Encima del cuerpo se encontró un bloque que produjo fracturaciones post mortem de los huesos de debajo.

En la tercera estructura analizada (UE 703), en su estrato basal (UE 704), se documenta un cráneo y un húmero derecho probablemente de la misma persona, no determinada sexualmente (individuo 9), pero de una edad de 35 años aproximadamente (fig. 6). 


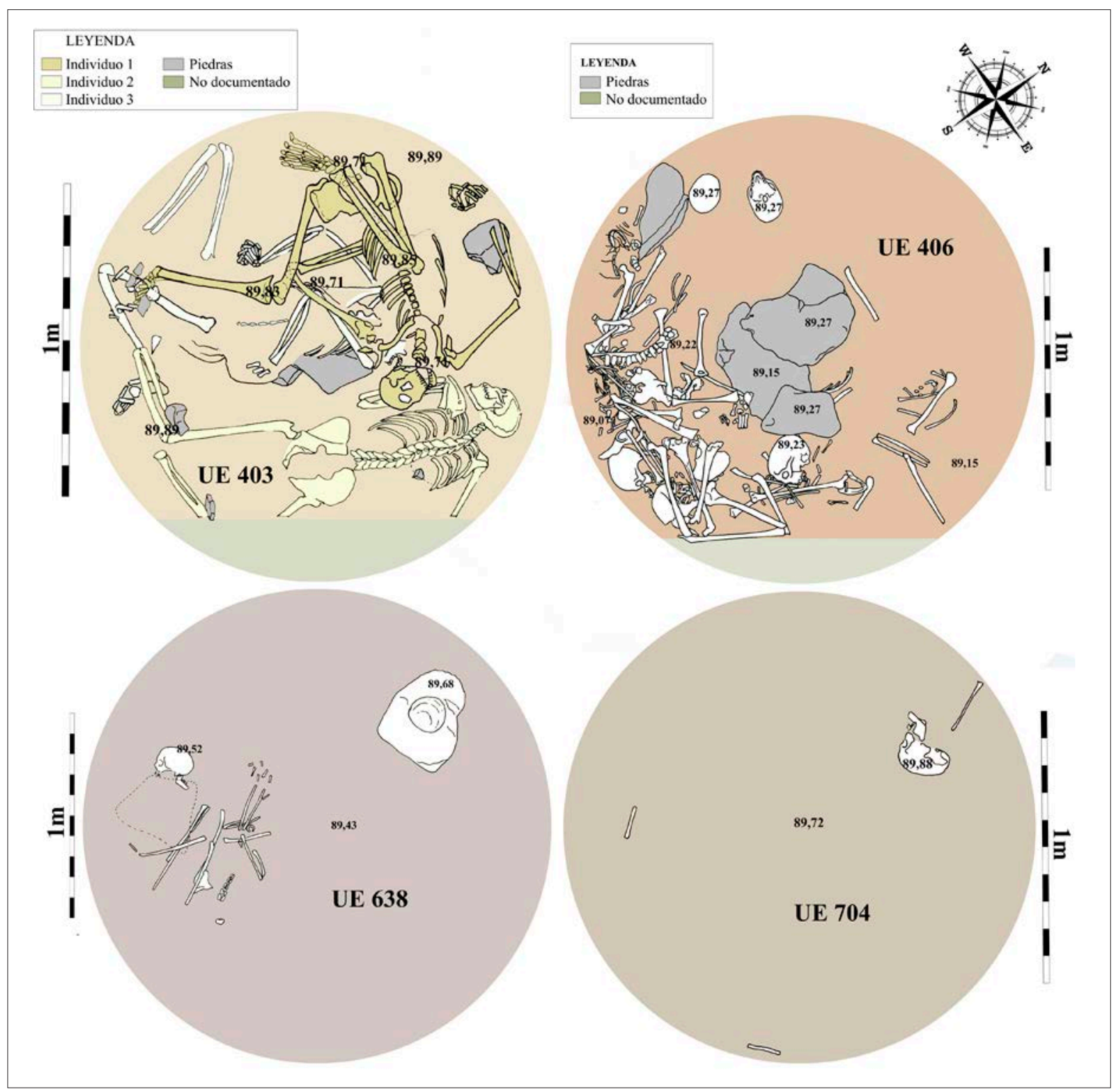

Fig. 6: Planimetrías de los depósitos funerarios.

Todos los sujetos muestran rasgos dentales muy similares recurrentes en los mismos dientes: apiñamientos de la región anterior inferior, desviaciones radiculares exageradas hacia distal, raíces fusionadas de premolares y molares, raíces accesorias y formas coronarias de terceros molares e incisivos muy similares. Sin embargo, los individuos 5, 6 y 7 tienen dientes en pala; los individuos 5 y 6 muestran esmalte ectópico (perlas y prolongaciones); y también se halló una cúspide supernumeraria en la pieza 17 del sujeto 4 .
El análisis paleopatológico advierte generalmente un nivel agravado de desgaste dental de las caras oclusales, que sigue una dirección horizontal con cierta inclinación diagonal de las caras vestibulares, indicando movimientos mandibulares horizontales relacionados con la masticación de alimentos duros y fibrosos, pero con cierto procesamiento. También existe desgaste en las caras proximales de las piezas dentales con una mayor retracción alveolar. El $37,56 \%$ de los alveolos muestran enfermedad periodontal a diferentes niveles que van desde la inflamación gingival 
hasta la periodontitis. El sarro cervical fue un gran marcador de esta enfermedad presente en todos los sujetos. 16 dientes (pertenecientes a los individuos 1, 3, 6, 7 y 9) tienen caries (la mayoría en primeros molares), todas localizadas en la región cervical de alguna cara proximal, extendiéndose en algunos casos hasta la cara oclusal. El caso más grave es del individuo 6 (unidad 406, estructura 400), que perdió varias piezas a causa de dos caries. Nueve piezas (de los individuos 3, 7 y 8) muestran displasias dentales, que pueden detectarse en sus incisivos y que se originaron cuando estas personas tenían entre 2 y 5 años, tras el periodo de destete y adaptación a una dieta sólida.

Por otro lado, se ha observado periostosis gomosa de intensidad variable en distintas regiones craneales de los sujetos. Esto podría estar relacionado con la periostitis y el cierre de todas las raíces dentales. Es posible que esta alteración se deba a la bacteria Treponema, manifestándose la patología en su tercera fase de manera monostótica. La falta de indicios, como la presencia de artrosis o necrosis y úlceras en la mucosa bucal, impiden confirmar dicha patología, pero los vestigios encontrados en las piezas dentales y los huesos craneales concuerdan parcialmente con la sífilis. Dada la relevancia e implicaciones históricas del posible hallazgo, se están llevando a cabo actualmente análisis específicos para confirmar la existencia de dicha enfermedad.

En cuanto a los huesos postcraneales, no existen roturas ante mortem significativas ni signos de violencia. En UE 406 (estructura 400) se han encontrado 5 huesos de brazos y antebrazos con arqueamientos que podrían ser el resultado de fracturas en tallo verde. Además, el individuo 4 tiene un orificio ovalado de $1,5 \times 1 \mathrm{~cm}$ consecuencia de una lesión traumática que se infectó levemente pero que se fue reparando hasta la muerte sin terminar de cerrarse.

\section{CONJUNTO CERÁMICO}

El peso del conjunto cerámico documentado en las tres estructuras es de $20.572 \mathrm{~g}$ (fig. 7). La estructura 400 contiene un conjunto total cuyo peso es de $4957 \mathrm{~g}$. La estructura 615 es la que contiene un conjunto cerámico mayor, concretamente de 15.569 g. En cambio, la estructura 703 sólo cuenta con un registro cerámico prehistórico de $46 \mathrm{~g}$.

Si se considera el peso relativo de los estratos funerarios respecto al resto de niveles de cada estructura, las unidades 403 y 406 -aquellas con enterramientos en la estructura 400- tienen mayores conjuntos cerámicos,

\begin{tabular}{|c|c|c|}
\hline Estructura & UE & Peso (g) \\
\hline 400 & 401 & 705 \\
\hline 400 & 402 & 421 \\
\hline 400 & 403 & 2809,5 \\
\hline 400 & 404 & 295 \\
\hline 400 & 405 & 167 \\
\hline 400 & 406 & 559,5 \\
\hline 615 & 616 & 9539 \\
\hline 615 & 637 & 4930 \\
\hline 615 & 638 & 1100 \\
\hline 703 & 704 & 46 \\
\hline
\end{tabular}

Fig. 7: Peso del conjunto cerámico para cada unidad estratigráfica.

especialmente la primera. En cambio, la tendencia es contraria en la estructura 615, donde el estrato con el enterramiento humano (638) tiene un conjunto significativamente menor que los de los estratos superiores.

Los dos estratos con enterramientos de la estructura 400 cuentan con conjuntos cerámicos relativamente similares entre sí. Ambos muestran un estado de fragmentación cerámica elevado y una distribución espacial aparentemente aleatoria, lo que reduce notablemente su interpretación como ofrendas propiamente dichas. No obstante, sí se asumen tales conjuntos como indicadores cronológicos, dada su coherencia interna y la ausencia de materiales posteriores. Ambas unidades son coherentes también en cuanto a la morfología cerámica de sus conjuntos (fig. 8). Predominan bordes sencillos con orientaciones tanto rectas como ligeramente entrantes y salientes, pero destacan significativamente aquellos con engrosamiento por el lado externo de labio. La mayoría de piezas son lisas y tienen pastas cuidadas y paredes relativamente finas. Son escasas las decoradas, representadas por incisiones y engobes rojos. Todas estas características son igualmente extensibles al resto de estratos de esta estructura (fig. 9), lo que indica su coherencia estratigráfica y cronológica. El principal indicador cerámico cronológico existente es el engrosamiento de lado externo del borde, que se insertaría según otros yacimientos de la región, en términos de calendario, en un intervalo máximo de la segunda mitad del V y la primera mitad del IV milenios cal BC.

El estrato con enterramiento de la estructura 615, es decir la unidad 638, cuenta con fragmentos cerámicos de pastas más toscas que las anteriores, así como de grosores 


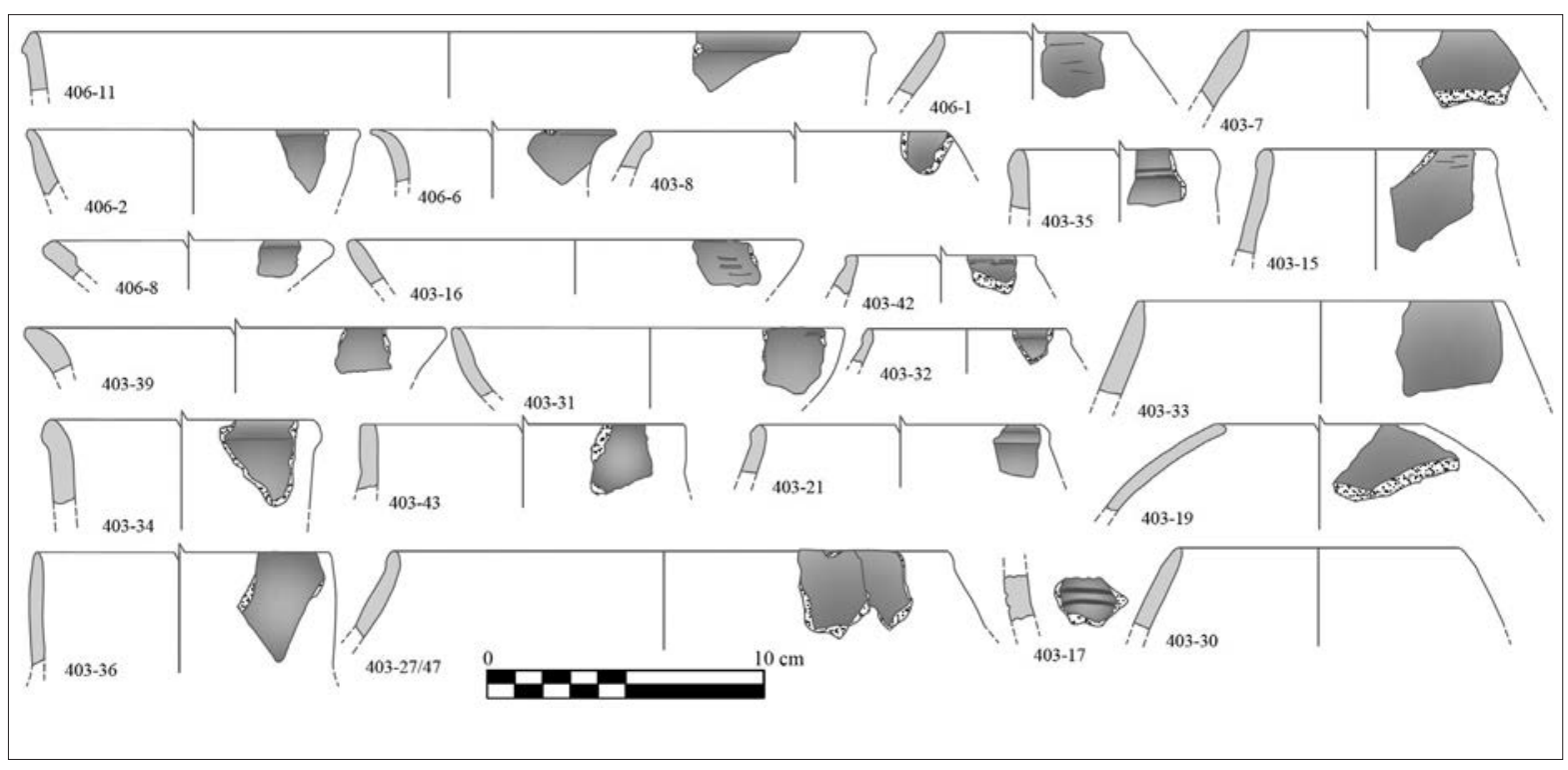

Fig. 8: Selección representativa del conjunto cerámico de las unidades estratigráficas 406 y 403.

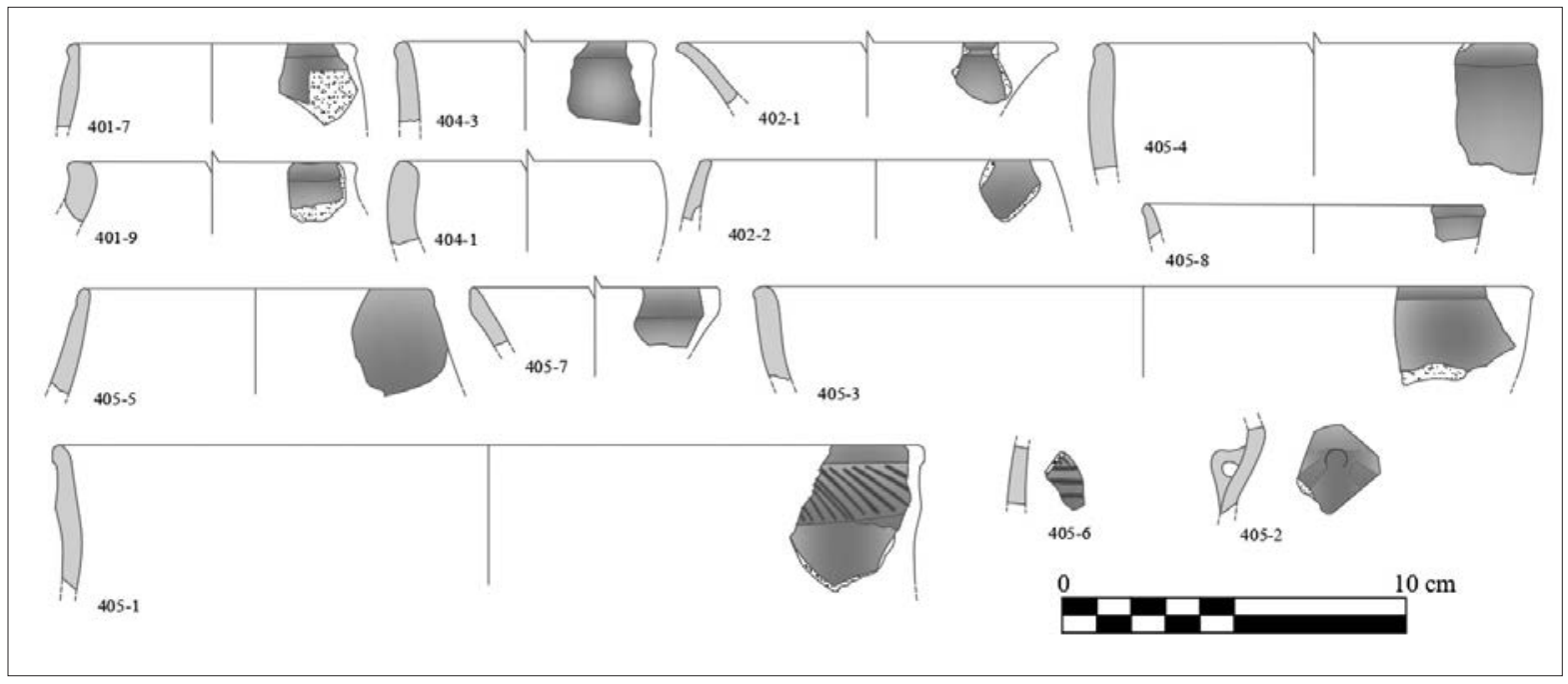

Fig. 9: Selección representativa del resto del conjunto cerámico de la estructura 400.

de pared y, sobre todo, de tamaño de recipientes notablemente mayores (fig. 10). Aunque hay bordes sencillos de orientación recta, así como ligeramente entrantes y salientes, destaca la existencia de recipientes abiertos, tazas o platos, con cierto aplanamiento en la base, algunos de ellos con paredes carenadas. Ninguna pieza presenta decoración. El resto de unidades posteriores son coherentes con la recién descrita (fig. 11). Abundan los recipientes abiertos carenados, y existe una mayor variabilidad de engrosamientos de los bordes, como los almendrados, y otras formas calcolíticas, así como un recipiente cilíndrico de paredes rectas y base plana. Estos indicadores cerámicos, algunos probablemente de Neolítico Final, pero en su mayoría de los inicios del Calcolítico, reflejarían en su conjunto una cronología posterior a la de la estructura 400 que, grosso modo, podría ubicarse dentro de la segunda mitad del IV cal BC y tal vez principios del III milenio. 


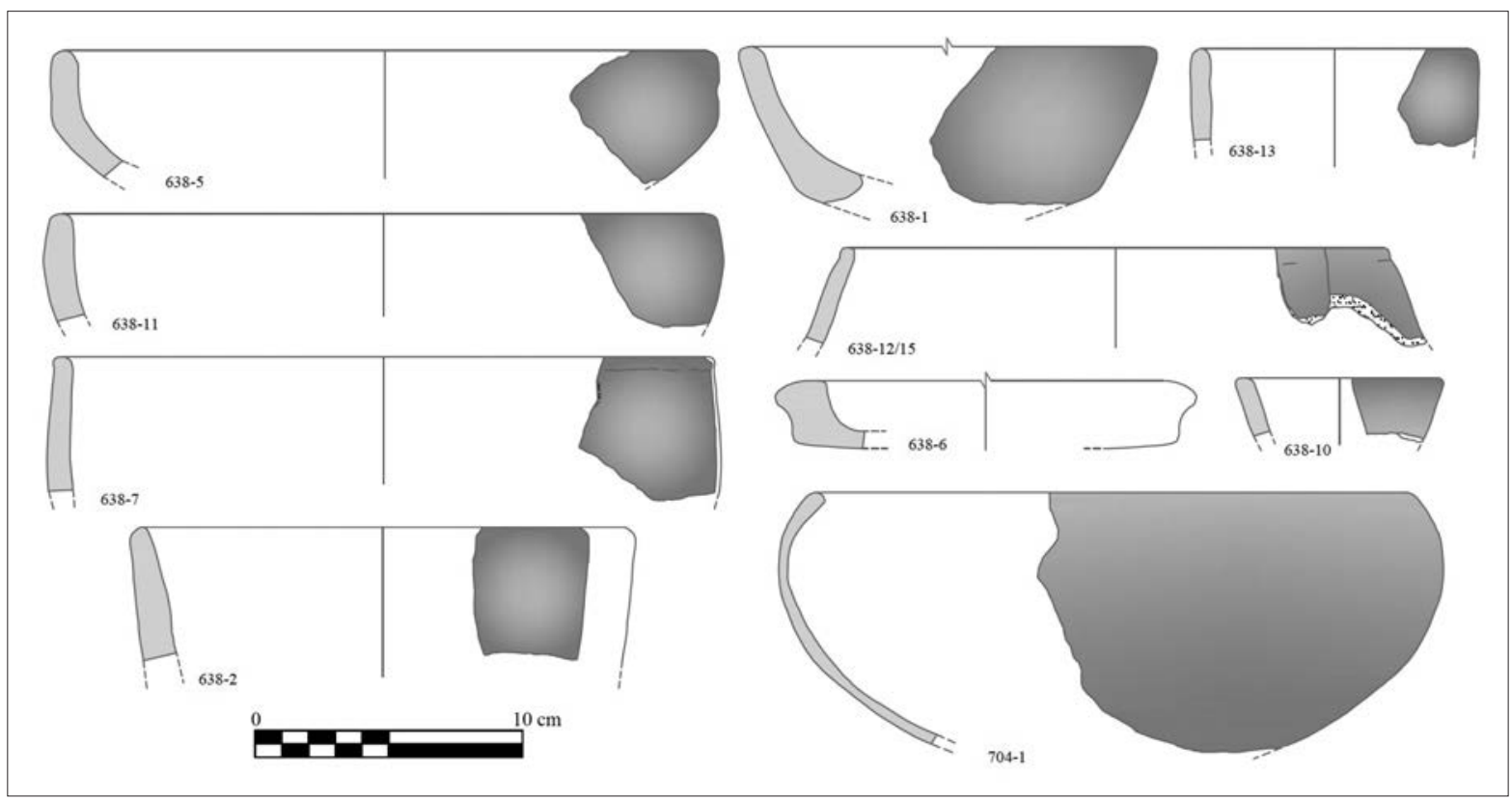

Fig. 10: Selección representativa del conjunto cerámico de las unidades estratigráficas 638 y 704.

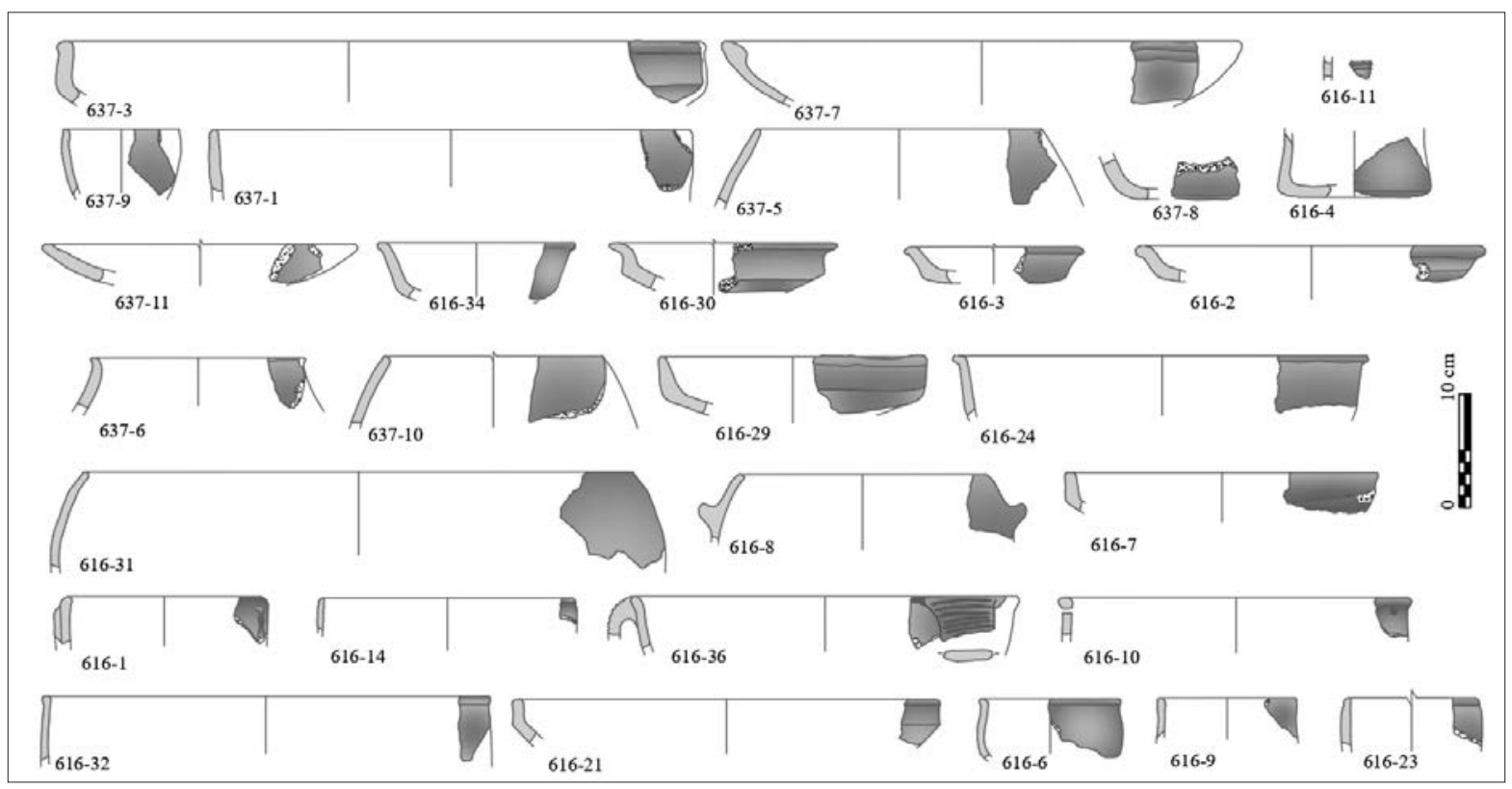

Fig. 11: Selección representativa del resto del conjunto cerámico de la estructura 615.

El estrato basal de la estructura 703 que contiene el cráneo y el húmero, es decir la unidad 704, apenas cuenta con cerámica. Los escasos fragmentos reflejan pastas relativamente toscas. Destaca un fragmento de gran tamaño de un recipiente hemisférico, de borde entrante y sin decoración (fig. 10, 704-1). Su adscripción cronológica es difícil de determinar, pero podría ser coherente con la fecha relativa sugerida para la estructura 615 . 


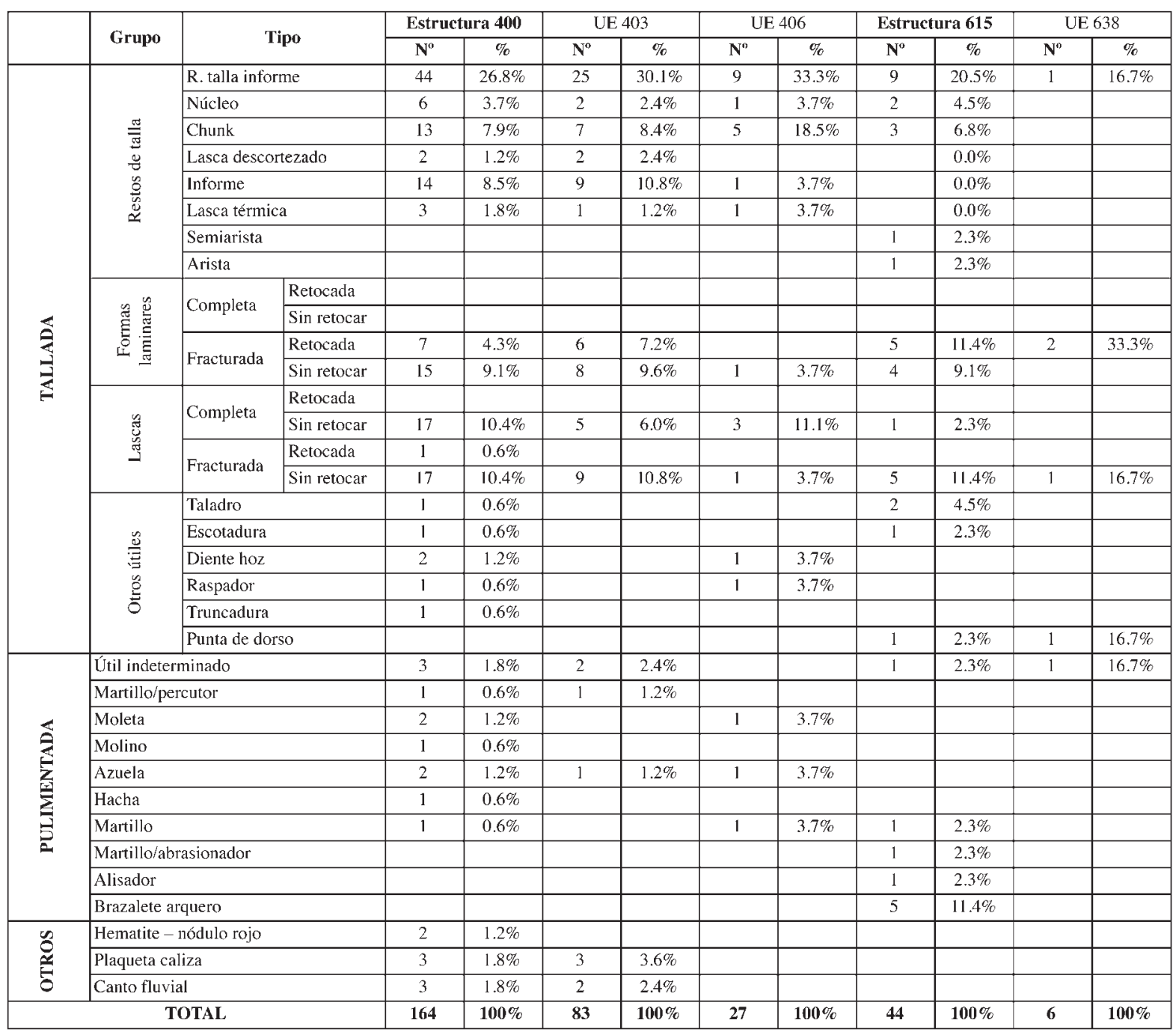

Fig. 12: Recuento del conjunto lítico total de las Estructuras 400 y 615 y del conjunto relativo a sus depósitos funerarios (unidades 403 , 406 y 638$)$.

\section{CONJUNTO LÍTICO}

El registro lítico está constituido por un total de 209 piezas procedentes de la totalidad de los estratos de las estructuras 400 y 615 . La estructura 703 no ha proporcionado industria lítica alguna (fig. 12).

A diferencia del registro cerámico, la estructura que contiene la mayor proporción del conjunto lítico es la 400, con un total de 164 elementos. Se mantienen tendencias opuestas en cuanto a la densidad de material que presentan las unidades donde yacen los enterramientos. Las unidades 403 y 406 acumulan mayor cantidad de material lítico que las otras de su misma estructura, mientras que 638 presenta un registro menor que el de los estratos superiores.
Las unidades con enterramientos de la estructura 400 presentan altos porcentajes de restos de talla, seguidos por formas laminares y lascas generalmente sin retoque. La industria lítica pulimentada está relativamente más representada en 406 que en 403 (11,1\% y 4,8\%, respectivamente). Este panorama es coherente con el conjunto general de la estructura 400, donde los núcleos y restos de talla, que incluyen informes, lasquitas de talla y retoque de longitud menor a $1 \mathrm{~cm}$ y productos de acondicionamiento, alcanzan el 50\% del total, seguidos por láminas y lascas de mayor tamaño sin retocar, piedra pulimentada, útiles definidos y nódulos colorantes.

Por otro lado, la unidad 638 de la estructura 615 presenta una predominancia de las formas laminares retocadas 
Fig. 13: Gráfico de curvas de la anchura y grosor de los soportes laminares.

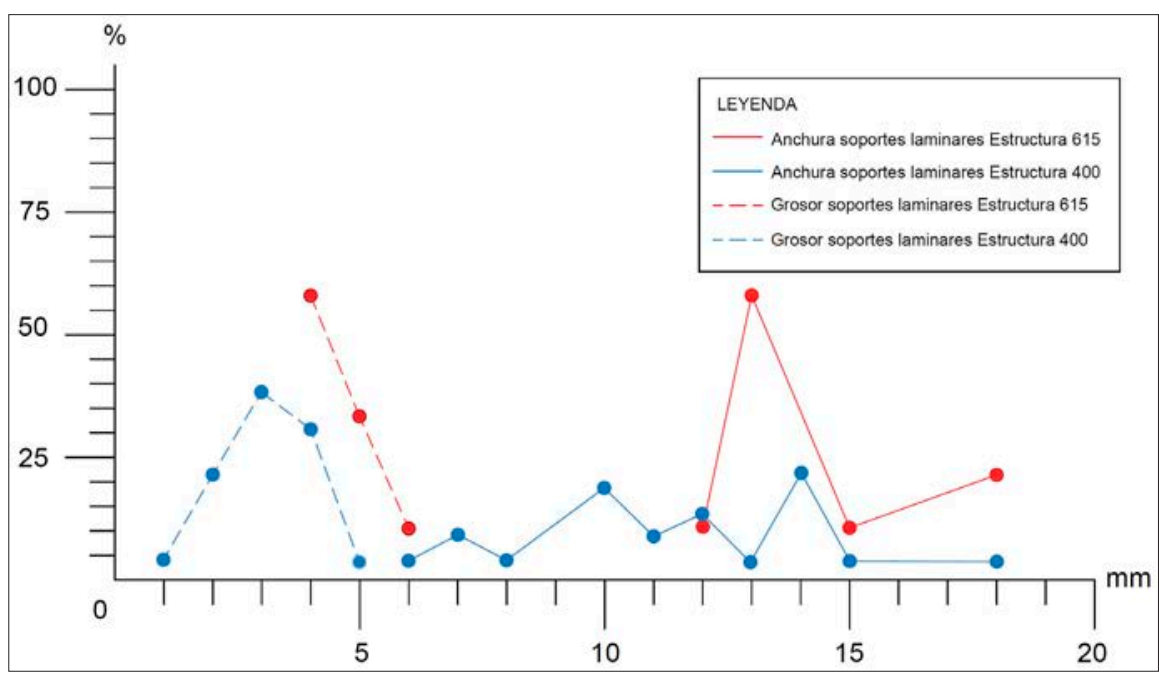

$(33,3 \%)$ sobre los demás grupos, estando los restos de talla y la piedra pulimentada reflejados en la misma proporción $(16,7 \%)$. La industria lítica de este estrato es tipológicamente coherente con la del resto, con presencia de láminas retocadas y útiles sobre lascas. No obstante, en el conjunto total de la estructura destacan cuantitativamente los restos de talla y productos de acondicionamiento.

En la estructura 400 predomina el retoque simple $(58,8 \%)$, y en la 615 los simples y abruptos, con idéntica proporción $(46,7 \%)$. La presencia de pátina vegetal sobre los filos conservados de las láminas es mayor en $615(7,5 \%)$ que en la estructura $400(3,6 \%)$. A la espera del análisis traceológico, esto podría indicar un mayor empleo del registro en tareas de procesado de cereal.

El análisis de los caracteres morfométricos (ancho y grosor) de las formas laminares indica unas medias superiores y menor variabilidad en el conjunto de la estructura 615 (fig. 13). La existencia de láminas de mayor tamaño y la frecuencia relativa de retoque abrupto en esta estructura pueden relacionarse con su datación relativa más avanzada, en torno a la transición del IV al III milenio cal BC según el análisis cerámico.
De hecho, en los estratos 616 y 637 se han documentado cinco brazales de arquero, elemento común en contextos funerarios del Calcolítico (Acosta 1995: 64; Murillo 1990: 61). Todos estos datos convergen pues con los resultados cerámicos en indicar que la estructura 400 es cronológicamente anterior a las estructuras 615 y 703: la primera de Neolítico final y las últimas del Calcolítico.

\section{FECHAS RADIOCARBÓNICAS}

Se han efectuado dataciones radiocarbónicas a los dos estratos funerarios de la estructura 400. Los análisis se han realizado a partir de dientes humanos en el Centro Nacional de Aceleradores de Sevilla. Las dos fechas obtenidas indican la muerte de los individuos datados, y se asumen como representativas de los depósitos funerarios de ambos estratos.

Los dos resultados se superponen (fig. 14) y son coherentes con las expectativas generadas por el análisis de los conjuntos cerámico y lítico. La muestra CNA4244 cuenta con un rango mayor que engloba íntegramente la cifra de la otra muestra. El rango máximo a dos sigmas es 3635-3500 cal BC. La convergencia de ambos resultados indica que los dos depósitos funerarios hubieron

\begin{tabular}{|c|c|c|c|c|c|c|c|c|c|c|c|}
\hline Código & ID & $\mathrm{UE}$ & Muestra & $\begin{array}{l}\text { \% Rend. } \\
\text { Extrac. }\end{array}$ & $\% \mathrm{C}$ & $\% \mathrm{~N}$ & $\mathrm{C}: \mathrm{N}$ & Fecha BP & $\delta^{13} \mathrm{C}(\% 0)$ & $\mathrm{Cal} \mathrm{BC}(2 \sigma)$ & $p$ \\
\hline CNA4244 & PAL16-2 & 403 & $\begin{array}{l}\text { Homo - Diente } \\
\text { individuo } 3\end{array}$ & 0,67 & 25,7 & 9,46 & 3,2 & $4770 \pm 32$ & $-14,26 \pm 1,50$ & $3635-3500$ & 0,78 \\
\hline CNA4243 & PALI6-1 & 406 & $\begin{array}{l}\text { Homo - Diente } \\
\text { individuo } 7\end{array}$ & 0,89 & 28,1 & 10,2 & 3,2 & $4800 \pm 33$ & $-19,15 \pm 1,50$ & $3609-3522$ & 0,77 \\
\hline
\end{tabular}

Fig. 14: Fechas radiocarbónicas efectuadas sobre muestras de la estructura 400. Calibración efectuada con Calib 7.0 (Reimer et al. 2013 ). 
de llevarse a cabo temporalmente próximos entre sí, y que el uso y relleno íntegro de la estructura 400 seguramente se produjo durante un lapso de tiempo relativamente reducido.

\section{DISCUSIÓN}

El hallazgo presentado se refiere a enterramientos en fosas de plantas circulares y secciones acampanadas, con dimensiones relativamente variables. Algunos se corresponden con inhumaciones primarias (unidades $403 \mathrm{y}$, tal vez, 638), que apenas muestran algunas desconexiones anatómicas debido a la propia descomposición del cadáver y a los movimientos y perdidas post mortem de algunas piezas óseas, sobre todo las más pequeñas, como los dientes, así como al efecto de algunas bioperturbaciones, como galerías de raíces y animales. Otros, sin embargo, parecen enterramientos secundarios (unidad 406), sin descartar un posible caso de restos aislados (unidad 704).

El individuo 8, depositado de forma aislada en el estrato basal de la estructura 615 , tenía superpuesto un bloque pétreo de gran tamaño, el cual le ocasionó numerosas fracturas post mortem. A pesar de dicha conexión, no podemos confirmar que dicho bloque se depositase a propósito sobre el cadáver durante el propio enterramiento, pues existen otros bloques similares justamente en el estrato posterior, uno de ellos con una suerte de cazoleta de gran tamaño. No obstante, los artefactos hallados en los estratos superpuestos al del enterramiento muestran el carácter funerario del depósito de esta fosa.

Sólo la estructura 703 muestra en su estrato basal restos parciales (cráneo y húmero) de un individuo, sin que pueda confirmarse que se trate ni siquiera de un enterramiento secundario, dado también el alto grado de afección de los estratos superiores.

Los individuos hallados en las tres estructuras presentadas muestran un rango de edad comprendido entre los 17 y los 35 años, si bien la mayoría se sitúa en torno a los 25 años. Al margen de la posible rotura craneal del individuo 4, de la unidad 406, no hay signos de violencia o fracturas graves de ningún tipo en los huesos estudiados.

Estas fosas se ubican a $300 \mathrm{~m}$ aproximadamente al $\mathrm{S}$ del Dolmen de El Palomar y a apenas $400 \mathrm{~m}$ al SO del Dolmen de Cañada Real (fig. 15). Este último se conoce desde hace medio siglo, pero apenas se publicó su contenido. Se trata de una galería cubierta con planta en forma de ' $\mathrm{L}$ ', con al menos dos niveles estratigráficos, cerámicas lisas, incisas e impresas de filiación neolítica ( $c f$. Cabrero et al. 2005: figs. 3-5), diversos objetos de piedra pulimentada y tallada, entre los que destacan láminas, cuentas y una azuela, y restos óseos (Ruiz Delgado 1985: 66 y ss.). De su expoliado y afectado depósito se puede reconstruir la existencia de al menos dos individuos adultos, una mujer y un hombre (Cabrero et al. 2005).

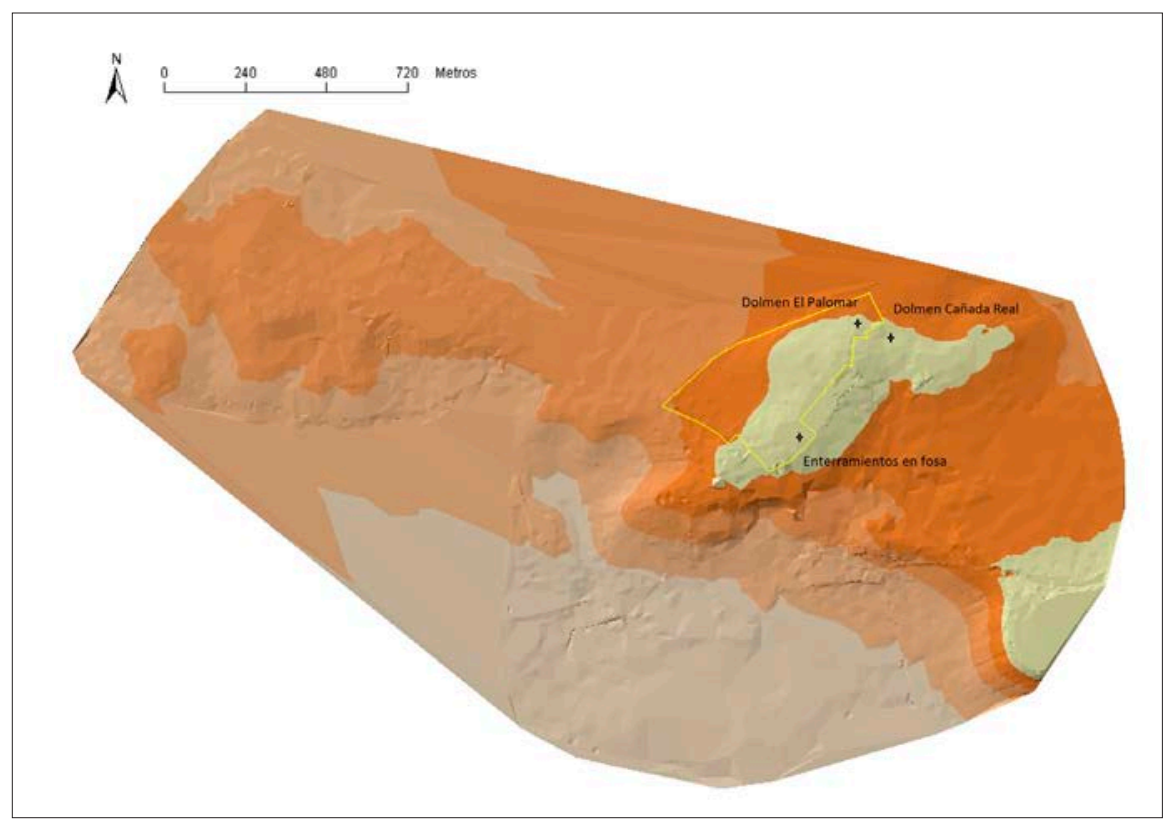

Fig. 15. Ubicación de los nuevos hallazgos respecto a los dólmenes de El Palomar y Cañada Real sobre plano topográfico 3D de Los Molares, a partir de Gómez et al. (2005: 59). 
El Dolmen de El Palomar se descubrió y excavó a principios de la década de 1980. Se trata igualmente de una galería cubierta en forma de 'L' con restos de al menos dos individuos de sexos femenino y masculino, en este caso con restos de ocre, y un conjunto artefactual compuesto por cerámicas decoradas de tradición neolítica y presencia de alguna forma calcolítica, objetos líticos tallados y escasos pulimentados, así como por algunos restos malacológicos (Cabrero et al. 1995; 1996). La existencia de material calcolítico, como algún borde almendrado o creciente de $\operatorname{arcilla}^{1}$ y supuestamente de puntas de flecha (Ruiz Delgado 1985: 67), indicarían el uso de esta tumba al menos hasta finales del IV milenio BC, pero muchos de sus artefactos y una fecha radiocarbónica disponible remontan cronológicamente su construcción hasta la primera mitad del IV milenio cal BC. Ésta, realizada sobre muestra ósea humana, arrojó un resultado de

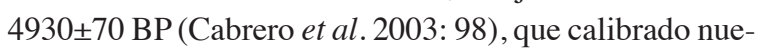
vamente ahora a dos sigmas (Reimer et al. 2013) muestra el intervalo 3823-3632 cal BC ( $p=0,848)$.

Esta fecha es similar a la obtenida ahora para los enterramientos de la estructura 400, cuyo rango máximo a dos sigmas, recuérdese, es 3635-3500 cal BC. Los conjuntos cerámicos de esta fosa y de los dólmenes son igualmente coherentes entre sí, predominando las formas cerradas y lisas (sólo están presente muy escasamente la decoración incisa y la aplicación de engobe rojo) y destacando los bordes ligeramente engrosados por el lado externo. Respecto a los conjuntos líticos, de los dólmenes de Cañada Real y El Palomar se conocen 25 y 14 piezas respectivamente, que incluyen restos de talla, útiles bien configurados e industria pulimentada en menor medida (Cabrero et al. 2003). La comparación entre los conjuntos de los dólmenes y los de las estructuras siliformes muestra diversas similitudes (figs. 16 y 17). Se encuentran formas funcionales de tradición antigua, como perforadores, raspadores y hojas de dorso, así como también muescas y denticulados, las cuales, a la espera de los análisis traceológicos, suelen vincularse tradicionalmente a labores agrícolas y al trabajo de la madera (Cabrero et al. 2003a: 118). También debe anotarse el predominio de restos de talla, incluyendo en este grupo núcleos, astillas o restos de talla informe, aristas y láminas y lascas sin retocar, según los criterios seguidos en Cabrero et al. (2003a). La estrategia de explotación de los núcleos es también coincidente entre los conjuntos de los dólmenes y de la estructura 400, porque la extracción de lascas para el aprovechamiento total de la materia prima ha deformado los propios núcleos (Cabrero et al. 2003a: 103). Y los tres sitios son también afines en que los útiles se elaboran sobre lascas y láminas de pequeño tamaño. Todo ello significa que ambos tipos de estructuras funerarias, las galerías megalíticas y al menos la fosa 400 , fueron coetáneas.

Las estructuras 615 y 703 parecen no obstante cronológicamente algo posteriores a la recién mencionada. Desafortunadamente no existen aún fechas radiocarbónicas procedentes de sus enterramientos. Sin embargo, sus conjuntos de artefactos son notablemente distintos. Respecto a la cerámica, destacan los recipientes de mayor tamaño, abiertos, carenados, de cierto aplanamiento en la base y notables engrosamientos a ambos lados del labio. Respecto a la lítica, la estrategia de explotación de los núcleos de la estructura 615 es distinta, porque aún conservan la forma prismática. Además, mientras que en los dólmenes y la fosa 400 se encuentran útiles elaborados sobre lascas y láminas de pequeño tamaño, en la estructura 615 los retoques se han llevado a cabo únicamente sobre formas laminares. Por tanto, los conjuntos arqueológicos de las estructuras 615 y seguramente 703 parecen mostrar mayor consonancia con el procedente del cercano asentamiento de El Amarguillo II, apenas a 1,5 km hacia el E, datado en el Calcolítico (Ruiz Delgado 1985: 63 y ss; Cabrero 1987; Cabrero et al. 1997; 2003b).

Estos hallazgos recientes aportan pues nuevas evidencias para mantener la hipótesis de una ocupación humana del área actual de Los Molares durante el IV milenio cal BC. Además de los monumentos megalíticos antes mencionados y conocidos desde hace décadas, hay que sumar ahora el descubrimiento de la fosa 400, igualmente de carácter funerario. Ambos tipos de enterramientos no obstante son notablemente distintos, lo que podría reflejar diferencias sociales entre los difuntos de estas estructuras, no sólo en la monumentalidad y mayor inversión constructiva de las galerías megalíticas, y en que éstas parecieron contener menos individuos, sino también en las características de la cultura material asociada y tal vez el posible uso diferencial de ajuar. Los objetos de piedras verdes, por ejemplo, sólo aparecen en los megalitos. Es interesante anotar que la materia prima sobre la que se elabora la industria lítica tallada es predominantemente sílex en la fosa, mientras que la caliza oolítica silificada es más característica de las citadas estructuras dolménicas. Por otro lado, en cambio, éstas apenas contienen industria pulimentada, a excepción de un par de hachas documentadas en Cañada Real, siendo proporcionalmente más abundante en la estructura siliforme. 


\begin{tabular}{|c|c|c|c|c|c|}
\hline & $\%$ & Cañada Real & El Palomar & Estr. 400 & Estr. 615 \\
\hline \multirow{14}{*}{ 志 } & RESTOS DE TALLA TOTAL & 0,68 & 0,5 & 0,799 & 0,578 \\
\hline & Núcleos & 0,08 & 0,143 & 0,037 & 0,044 \\
\hline & Láminas + lascas & 0,56 & 0,357 & 0,299 & 0,222 \\
\hline & Esquirlas & 0,04 & & 0,463 & 0,267 \\
\hline & Aristas & & & & 0,044 \\
\hline & ÚTILES TOTAL & 0,16 & 0,429 & 0,085 & 0,2 \\
\hline & Raspadores & 0,04 & & 0,006 & \\
\hline & Lascas ret. & 0,08 & 0,071 & 0,006 & \\
\hline & Láminas ret. & 0,04 & 0,143 & 0,043 & 0,111 \\
\hline & Denticulados & & 0,143 & 0,024 & 0,022 \\
\hline & Perforadores & & 0,071 & & \\
\hline & Hojas de dorso & & & & 0,022 \\
\hline & Taladros & & & 0,006 & 0,044 \\
\hline & Indeterminados & & & & \\
\hline \multirow{10}{*}{ 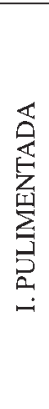 } & Azuelas / Hachas & 0,08 & & 0,018 & \\
\hline & Indeterminados & 0,04 & 0,071 & 0,018 & 0,044 \\
\hline & Frag. Cuarcita & 0,04 & & & \\
\hline & Molienda & & & 0,018 & \\
\hline & Martillo & & & 0,012 & $\mathbf{0 , 0 4 4}$ \\
\hline & Alisador & & & & 0,022 \\
\hline & Brazalete arquero & & & & 0,111 \\
\hline & Nódulo rojo & & & 0,012 & \\
\hline & Canto fluvial & & & 0,018 & \\
\hline & Plaqueta caliza & & & 0,018 & \\
\hline
\end{tabular}

Fig. 16: Frecuencias relativas de los tipos líticos en los dólmenes y fosas.

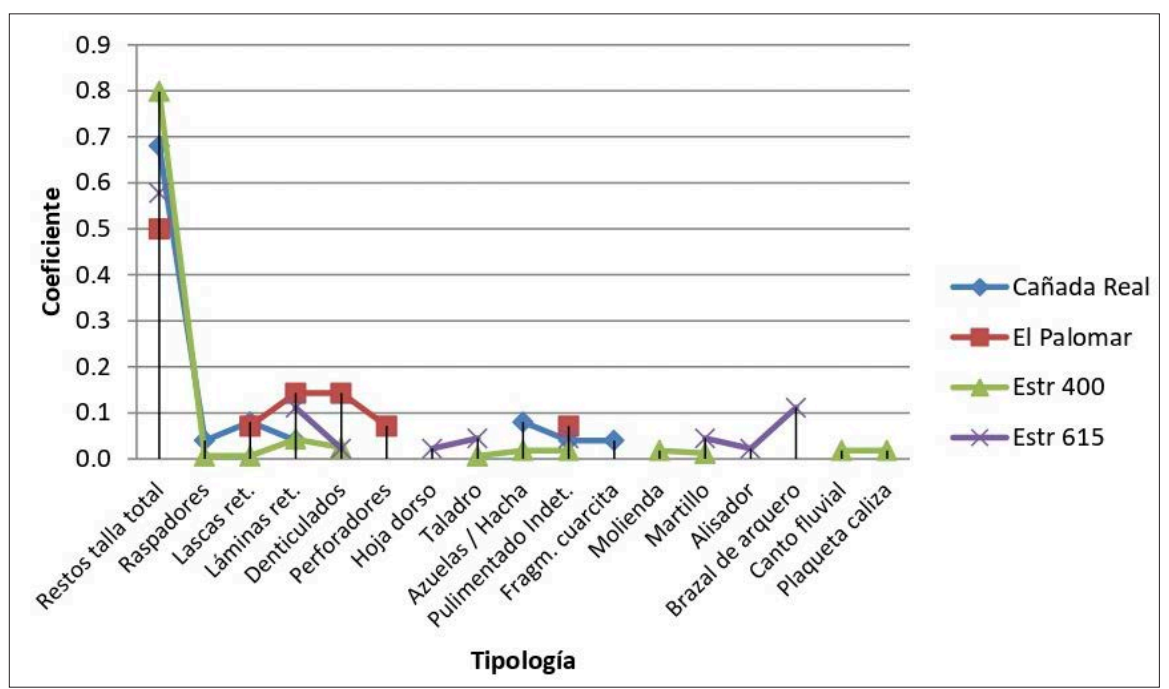

Fig. 17: Gráfica comparativa entre los cuatro conjuntos líticos.

Desafortunadamente, no se ha podido realizar un estudio comparativo sistemático entre los restos osteológicos de los difuntos de una y otras estructuras. No obstante, a pesar de las diferencias antes mencionadas, en los huesos hallados en el Dolmen de Cañada Real se han documentado nódulos de Schmorld, entesopatías y hernias discales en adultos jóvenes (Cabrero et al. 2005: 69). En los silos, probablemente a causa de la alta destrucción post mortem, no se han hallado signos de sobrecargas musculares. 
Queda abierta la cuestión de si la suave elevación donde hoy se emplaza la localidad de Los Molares hubiese contado también con alguna zona de asentamiento neolítico. No hemos tenido acceso a la documentación del resto de estructuras negativas excavadas, y no puede descartarse la existencia de estructuras y áreas de hábitat. Cerca de nuestra Manzana 16, se tiene constancia de hallazgos arqueológicos previos en las fincas adyacentes por el E, durante la urbanización de varias manzanas residenciales y el instituto público Francisco Rivero. Desafortunadamente, no se realizaron excavaciones arqueológicas, y tampoco tenemos constancia de los materiales exhumados.

Se conocen hasta el momento escasos hallazgos funerarios neolíticos coetáneos a la estructura 400 en el contexto regional de la margen izquierda de la cuenca del Bajo Guadalquivir. Datado en la primera mitad del IV milenio cal BC, existe sólo el dolmen de Alberite, en la necrópolis de Villamartín, apenas $30 \mathrm{~km}$ al S, uno de los megalitos ibéricos con fechas más altas en la actualidad (Ramos y Giles 1996). En la línea costera gaditana se conoce Campo de Hockey, en San Fernando, donde existen enterramientos propiamente en fosa datados en esta época (Vijande 2009; 2010). En plena sierra gaditana se han adscrito tentativamente en torno a este momento restos de enterramientos en la cueva VR-15, en Villaluenga del Rosario, pero en un contexto arqueológico afectado por remociones y sin datación radiocarbónica (Santiago et al. 1997; Gutiérrez López et al. 2000: 160).

El registro funerario es mucho más sustancioso para la segunda mitad del IV milenio cal BC, en la transición entre los periodos tradicionalmente denominados Neolítico Final y Calcolítico. De $\mathrm{N}$ a $\mathrm{S}$ en la zona de estudio, se conocen enterramientos en fosa en Carmona (Conlin 2017: 22-35), y apenas $20 \mathrm{~km}$ al S de Los Molares existen noticias de otros enterramientos en fosa en Las Aguzaderas (El Coronil) (Ruiz Delgado 1985: 69 y ss). En Arcos de la Frontera, se conocen las evidencias procedentes de El Jadramil (Lazarich 1999; Lazarich y Richarte 2003) y la necrópolis de las Valderas (Lazarich et al. 2001). En la campiña jerezana se localizan El Trobal (Jerez de la Frontera) (González 1986) y Torremelgarejo (González y Ramos 1990). Por último, en la línea costera gaditana se encuentra La Esparragosa (Chiclana de la Frontera) (Ramos et al. 2008; Vijande et al. 2018). Al margen de los enterramientos en fosa, existen también para esta época algunos enterramientos en megalitos. Además de la presunta fase de uso más tardía de El Palomar y Cañada Real, existen enterramientos supuestamente coetáneos en los dólmenes de El Gandul (Alcalá de Guadaira) (Hurtado y Amores 1984), Cruz del Gato I, II y III (Utrera) (Salas y Barrionuevo 2000) y El Juncal (Ubrique) (Gutiérrez López 2007).

La mayor cantidad de sitios funerarios (así como de asentamientos) durante la segunda mitad del IV milenio cal $\mathrm{BC}$ refleja un crecimiento demográfico patente en todo el $\mathrm{S}$ de la península Ibérica, historiográficamente relacionado con la denominada revolución de los productos secundarios. Este aumento se intensifica aún más a partir de la transición al III milenio cal BC, en el Calcolítico, cuando se generalizan los grandes asentamientos, así como las necrópolis megalíticas.

En este sentido toman especial relevancia las evidencias arqueológicas, antiguas y actuales, del entorno megalítico de Los Molares, donde tanto enterramientos en dólmenes como en fosa están presentes desde la primera mitad del IV milenio cal BC. Se trata pues, al igual que los dólmenes de Villamartín y de Antequera, de otro de los núcleos pioneros del megalitismo andaluz. Por tanto, constituye un caso de estudio importante de cara al conocimiento de las últimas poblaciones neolíticas y de las notables transformaciones sociales que indica el registro arqueológico ibérico del IV milenio cal BC.

\section{NOTA}

1. Archivo documental de la Profesora Dña. Rosario Cabrero García, Departamento de Prehistoria y Arqueología, Universidad de Sevilla.

\section{AGRADECIMIENTOS}

Este trabajo ha sido realizado por el proyecto High-resolution chronology and cultural evolution in the South of the Iberian Peninsula (circa 7000-4000 cal BC): a multiscalar approach (PGC2018096943-A-C22), financiado por: FEDER/Ministerio de Ciencia e Innovación - Agencia Estatal de Investigación.

La intervención arqueológica de 2005 y 2006 en la finca El Palomar se llevó a cabo en el marco de la empresa GEAS bajo la dirección de Ezequiel Gómez Murga y Gilberto Rodríguez González. La revisión de la cultura material del dolmen de El Palomar ha usado el Archivo documental de Dña. Rosario Cabrero García, querida compañera del Departamento de Prehistoria y Arqueología de la Universidad de Sevilla, fallecida hace unos años, la cual dedicó parte de sus investigaciones a esta zona de Los Molares. Ricardo 
Ortega Ruiz, del Instituto de Formación Profesional en Ciencias Forenses, prestó su ayuda en el diagnóstico paleoantropológico, y Juan Carlos Vera, de la Universidad de Huelva, en la definición tipológica del conjunto lítico. En el marco de EvoCultura - Asociación universitaria para el estudio de la evolución del comportamiento humano y la diversidad cultural, diversos entonces estudiantes de la Facultad de Geografía e Historia colaboraron en el dibujo de los materiales cerámicos: Manuel J. Díaz, Pablo Franco, Araceli Barrera, David López, Patricia Virino y Jericó Mancera. Por último, se agradece a los editores de la revista Sagvntvm el interés en este trabajo, y a dos revisores anónimos sus comentarios constructivos sobre el manuscrito inicial.

\section{BIBLIOGRAFÍA}

ACOSTA, P. (1995): Las culturas del neolítico y calcolítico en Andalucía Occidental, Espacio, Tiempo y Forma, Serie I, 8, 33-80.

ARTEAGA, O.; SCHULZ, H. D.; ROOS, A. M. (1995): El problema del 'Lacus Ligustinus'. Investigaciones geoarqueológicas en torno a las Marismas del Bajo Guadalquivir, Tartessos 25 años después, 1968-1993, Jerez de la Frontera, 99-135.

BAGOLINI, B. (1968): Ricerche sulle dimensioni dei manufatti litici prehistorici non ritoccati, Annali dell'Universitá di $\mathrm{Fe}$ rrara, Sezione 15, 1 (10), 195-219.

BORJA, F.; BORJA, C.; SANCHO, Á. J.; VARGAS, E. G. (2018): Evolución de la llanura aluvial del bajo Guadalquivir durante el Holoceno medio-superior. Geoarqueología y reconstrucción paleogeográfica de la vega de Itálica (Sevilla, España), Boletín geológico y minero 129 (1), 371-420.

BERNALDO-QUIRÓS, F.; CABRERA, V.; CACHO, C.; VEGA, L. G., (1981): Proyecto de análisis técnico para las industrias líticas, TP 38, 9-37.

BROTHWELL, D. R. (1993): Desenterrando huesos. La excavación, tratamiento y estudio de restos del esqueleto humano, Madrid.

BURNS, K. R. (2008): Manual de Antropología Forense, Barcelona. CABRERO, R. (1987): Informe preliminar sobre las excavaciones arqueológicas realizadas en el yacimiento de Amarguillo II (Los Molares, Sevilla), Anuario arqueológico de Andalucía 1986, II, 180-185.

CABRERO, R. (1988): El fenómeno megalítico en Andalucía occidental, Tesis Doctoral, Universidad de Sevilla.

CABRERO, R. (1990): El poblado de la Edad del Cobre denominado Amarguillo II (Los Molares, Sevilla). Informe preliminar tras la excavación sistemática de 1987, Anuario arqueológico de Andalucía 1987, 276-277.

CABRERO, R.; AMBROSIANI, J.; GUIJO, J. M.; GÓMEZ MURGA, E. (2005): Estudio de restos humanos procedentes del Dolmen de Cañada Real depositados en el Departamento de Anatomía y Embriología Humanas de la Facultad de Medicina de la Universidad de Sevilla, Spal 14, 59-74.
CABRERO, R.; OLIVA, D.; MALGOSA, A.; SANFONT, S.; RUIZ MORENO, M. T.; SUBIRÁ, M. E.; SABATÉ, I.; BARDERA, R. (1995): Arqueometría antropológica en el sepulcro megalítico de El Palomar: Contribución al conocimiento histórico de la campiña sevillana, Spal 4, 69-80.

CABRERO, R.; PAJUELO, A.; GÓMEZ MURGA, E.; LÓPEZ ALDANA, P. M. (2003b): Objetos diversos procedentes del poblado calcolítico de Amarguillo II (Los Molares, Sevi1la), Spal 12: 145-178.

CABRERO, R.; RUIZ, M. T.; BLAS, L. (1996): Artefactos de tradición neolítica en sociedades prehistóricas de la provincia de Sevilla: Cronología y cambio cultural, Rubricatum 1, 191-200.

CABRERO, R.; RUIZ, M. T.; CUADRADO, L. B.; SABATÉ, I. (1997): El poblado metalúrgico de Amarguillo II en Los Molares (Sevilla) y su entorno inmediato en la campiña: últimas analíticas realizadas, Anuario Arqueológico de Andalucía 1993, 131-141.

CABRERO, R.; VALVERDE, M.; PASCUAL, E.; OLIVA, D.; GÓMEZ MURGA, E. (2003a): La necrópolis megalítica de Los Molares: estudio lítico preliminar de la industria tallada y pulimentada de Cañada Real y El Palomar: análisis de caracterización de la materia prima, morfológico, técnico y tipométrico, Spal 12, 97-124.

CAMPILLO, D. (1993): Paleopatología: los primeros vestigios de la enfermedad, Barcelona.

CAMPILLO, D.; SUBIRÁ, M. E. (2004): Antropología física para arqueólogos, Barcelona.

CARRIAZO, J. M. (1974): Protohistoria de Sevilla. Guadalquivir, Sevilla.

CARVAlHO, A. F. (1998): Talhe da pedra no Neolítico antigo do Maciço Calcário das Serras d'Aire e Candeeiros (Estremadura Portuguesa). Um primeiro modelo tecnológico e tipológico, Lisboa.

CARVALHO, A. F.; GIBAJA, J. F. (2005): Talhe da pedra no Neolítico antigo do Maciço Calcário Estremenho (Portugal): matérias-primas, tecnologia e análise funcional, III Congreso del Neolítico en la Península Ibérica (P. Arias, R. Ontañón, C. García-Moncó, eds.), Santander, 373-382.

CHIMENOS, E.; SAFONT, S.; ALESAN, A.; ALFONSO, J.; MALGOSA, A. (1999): Propuesta de protocolo de valoración de parámetros en Paleodontología, Gaceta dental, Industria y profesiones 102, 44-52.

CONLIN, E. (2017): Rituales y elementos simbólicos del IV al III milenio a.C. Carmona, Religión y espiritualidad en Carmona. De la Prehistoria a los tiempos contemporáneos. Actas del X Congreso de Historia de Carmona (M. González Jiménez, A. Caballos, eds.), Sevilla, 21-48.

EGOCHEAGA, J. E.; TRABAZO, R. (2000): Revisión metodológica del análisis de restos óseos en el estudio de paleodietas, Tendencias actuales de Investigación en la Antropología Física Española (L. Caro, H. Rodríguez, E. Sánchez, B. López, M. J. Blanco, coords.), León, 115-124. 
GÓMEZ, E.; PÉREZ, P.; RODRÍGUEZ, G.; CABRERO, R. (2005): Finca El Palomar. Resultados arqueológicos iniciales. Fase I. Memoria depositada en la Delegación Provincial de Cultura de Sevilla.

GONZÁLEZ, R. (1986): El yacimiento de El Trobal (Jerez de la Frontera, Cádiz). Nuevas aportaciones a la cultura de los silos de la Baja Andalucía, Anuario Arqueológico de Andalucía 3, 82-88.

GONZÁLEZ, R.; RAMOS, J. (1990): Torre Melgarejo, un sepulcro de inhumación colectiva en los Llanos de Caulina (Jerez, Cádiz), Anuario Arqueológico de Andalucía 1988, III, 84-98.

GUTIÉRREZ LÓPEZ, J. M. (2007): Un avance de la excavación del sepulcro megalítico de El Juncal (Ubrique, Cádiz), Revista Atlántica-Mediterránea de Prehistoria y Arqueología Social 9, 291-301.

GUTIÉRREZ LÓPEZ, J. M.; REINOSO, M. C.; AGUILERA, L.; SANTIAGO, A. (2000): Un balance del Neolítico de las Subbéticas Occidentales al final del Milenio, Actas del I Congreso Andaluz de Espeleología (A. Santiago, A. Martínez, J. Mayoral, eds.), Sevilla, 151-175.

HARRIS, E. C. (1991): Principios de estratigrafía arqueológica, Barcelona.

HURTADO, V.; AMORES, F. (1984): El tholos de Las Canteras y los enterramientos del Bronce en la necrópolis de El Gandul (Alcalá de Guadaira, Sevilla), CPUG 9, 147-174.

ISIDRO, A.; MALGOSA, A. (2003): Paleopatología: la enfermedad no escrita, Barcelona.

JUAN-CABANILLES, J. (2008): El utillaje de piedra tallada en la Prehistoria reciente valenciana. Aspectos tipológicos, estilísticos y evolutivos, Trabajos Varios. S.I.P. 109, València.

LAPLACE, G. (1966): Recherches sur l'origine et l'évolution des complexes leptolithiques, París.

LAZARICH, M. (1999): El campaniforme en Andalucía occidental, Cádiz.

LAZARICH, M.; BUENO, O.; RICHARTE, M. (2001): Estudio antropológico y de los productos arqueológicos hallados en la Necrópolis de Las Valderas (Arcos de la Frontera, Cádiz), depositados en los fondos del Museo Provincial de Cádiz, Anuario Arqueológico de Andalucía II, Actividades sistemáticas y puntuales, 83-91.

LAZARICH, M.; RICHARTE, M. J. (2003): El Jadramil (Arcos de la Frontera): estudio arqueológico de un asentamiento agrícola en la campiña gaditana, Cádiz.

LÓPEZ LAZARO, S.; VICIANO, J.; ALAMÁN, I.; BOTELLA, M.C. (2013): Algunos rasgos dentales básicos en la identificación humana, Boletín Galego de Medicina Legal e Forense 19, 45-51.

MARTÍNEZ, G.; AFONSO, J. A. (2008): L'évolution des ensembles d'artéfacts en pierre taillé pendant la Préhistoire récente au Sud-Est de la Péninsule ibérique, Les industries lithiques taillées des IVe et IIIe millénaires en Europe Occidentale (M. H. Dias-Meirinho, V. Léa, K. Gernigon, P. Fouéré, F. Briois, M. Bailly, eds.), Oxford, 291-308.
MURILLO, J. F. (1990): Estado de la cuestión sobre el poblamiento durante el calcolítico y la edad del bronce en las Subbéticas Cordobesas, Anales de Arqueología Cordobesa 1, 53-80.

RAMOS, J.; GILES, F. (1996): El dolmen de Alberite: Villamartín: aportaciones a las formas económicas y sociales de las comunidades neolíticas en el noroeste de Cádiz, Cádiz.

RAMOS, J.; PÉREZ, M.; CLEMENTE, I.; GARCÍA, V.; RUIZ, M. B.; GIL, M. J.; VIJANDE, E.; CASIMIRO, M. HERNANDO, J. A.; ZABALA, C. (2008): La Esparragosa (Chiclana de la Frontera). Un asentamiento con campo de silos en la campiña de Cádiz, del IV ${ }^{\circ}$ milenio ane, IV Congreso del Neolítico Peninsular (M. S. Hernández, J. A. Soler, J. A. López Padilla, eds.) Alicante, 385-392.

REIMER, P. J.; BARD, E.; BAYLISS, A.; BECK, J. W.; BLACKWELL, P. G.; BRONK-RAMSEY, C.; GROOTES, P. M.; GUILDERSON, T. P .; HAFLIDASON, H.; HAJDAS, I.; HATT, C.; HEATON, T. J .; HOFFMAN, D. L.; HOGG, A. G.; HUGHEN, K. A.; KAISER, K. F.; KROMER, B.; MANNING, S. W.; NIU, M.; REIMER, R. W.; RICHARDS, D. A.; SCOTT, E. M.; SOUTHON, J. R.; STAFF, R. A.; TURNEY, C. S. M.; VAN DER PLICHT, J. (2013): IntCal13 and Marine13 radiocarbon age calibration curves 0-50,000 years cal BP, Radiocarbon 55 (4), 1869-1887.

DOI: https://doi.org/10.2458/azu_js_rc.55.16947

RUIZ DELGADO, M. M. (1985): Carta arqueológica de la campiña sevillana. Zona sureste I, Sevilla.

SALAS, J.; BARRIONUEVO, F. J. (2000): El catálogo de dólmenes de la provincia de Sevilla, PH: Boletín del Instituto Andaluz del Patrimonio Histórico 31, 179-187.

SANTIAGO, A.; GUTIÉRREZ, J. M.; GILES, F.; PEDROCHE, A.; MENDOZA, D.; PRIETO, M. C. (1997): Arte paleolítico en la serranía de Grazalema. La cavidad VR-15, Revista de Arqueología 195, 10-19.

VIJANDE, E. (2009): El poblado de Campo de Hockey (San Fernando, Cádiz): resultados preliminares y líneas de investigación futuras para el conocimiento de las formaciones sociales tribales en la Bahía de Cádiz (tránsito V-IV milenios ane), Revista Atlántica-Mediterránea de Prehistoria y Arqueología Social 11, 265-284.

VIJANDE, E. (coord.) (2010): La necrópolis neolítica de Campo de Hockey. La muerte hace 6 mil años en la Isla de San Fernando, San Fernando.

VIJANDE, E.; RAMOS, J.; PÉREZ, M.; MORENO, A.; CANTILLO, J. J.; DOMÍNGUEZ, S.; ALMISAS, S.; RIQUELME, J. A.; SORIGUER, M.; CLEMENTE, I. GARCÍA, V.; BARRERA, A.; RUIZ, B.; GIL, M. J.; FERNÁNDEZ, D. (2018): Estudio interdisciplinar de la tumba AV del asentamiento neolítico de La Esparragosa (Chiclana de la Frontera, Cádiz, España), Arqueología Iberoamericana 37, 40-47.

VV. AA. (1982): Arqueología 81. Memoria de las actuaciones programadas en el año 1981, Madrid. 